\title{
Neuroprotective effects of paeoniflorin: an emerging concept in neurology
}

\author{
Shailendra Kapoor \\ Private practice, Chicago, IL, USA
}

Folia Neuropathol 2013; 51 (1): 92
DOI: 10.5114/fn.2013.34201

The above examples clearly illustrate the neuroprotective effects of paeoniflorin.

\section{References}

1. Cao BY, Yang YP, Luo WF, Mao CJ, Han R, Sun X, Cheng J, Liu CF. Paeoniflorin, a potent natural compound, protects PC12 cells from MPP+ and acidic damage via autophagic pathway. J Ethnopharmacol 2010; 131: 122-129.

2. Hino H, Takahashi H, Suzuki Y, Tanaka J, Ishii E, Fukuda M. Anticonvulsive effect of paeoniflorin on experimental febrile seizures in immature rats: possible application for febrile seizures in children. PLoS One 2012; 7: e42920.

3. Liu J, Jin DZ, Xiao L, Zhu XZ. Paeoniflorin attenuates chronic cerebral hypoperfusion-induced learning dysfunction and brain damage in rats. Brain Res 2006; 1089: 162-170.

4. Liu Y, Cui G, Zhang Y, Gao X, Gao Y. Mechanism of protective effect of pretreatment of paeoniflorin on injured cortical neurons with corticosterone. Zhongguo Zhong Yao Za Zhi 2010; 35: 2457-2459.

5. Sun R, Wang K, Wu D, Li X, Ou Y. Protective effect of paeoniflorin against glutamate-induced neurotoxicity in PC12 cells via Bcl-2/Bax signal pathway. Folia Neuropathol 2012; 50: 270-276.

6. Tang NY, Liu CH, Hsieh CT, Hsieh CL. The anti-inflammatory effect of paeoniflorin on cerebral infarction induced by ischemia-reperfusion injury in Sprague-Dawley rats. Am J Chin Med 2010; 38: 51-64. 